\title{
Curative Effect of Parinari curatellifolia Leaf Extract on Epiglottitis
}

\author{
Eze, Henry Tochukwu ${ }^{1}$ and Wurochekke, Abdullahi Usman ${ }^{2}$. \\ Department of Biochemistry, Modibbo Adama University of Technology, Yola, \\ PMB 2076, Yola, Adamawa State, Nigeria.
}

\begin{abstract}
The curative effect of Parinari curatellifolia leaf extract on epiglottitis was investigated. The air dried leaf of Parinari curatellifolia was extracted using the soxhlet extractor. Crude extract of the plant was found to be rich in phytochemicals of medicinal importance such as alkaloids, tannins, saponins, flavonoids, steroids, and cardiac glycosides. Acetic acid extract had the highest antimicrobial activity with zones of inhibition ranging from $20.0 \pm 0.6$ to $28.3 \pm 0.3$ against the test organisms. This activity was not significantly $(P<0.05)$ different from leofloxacin with zones of inhibition ranging from $25.0 \pm 0.6$ to $29.3 \pm 0.3$ which was the highest activity among the standard drugs used. The minimum inhibitory concentration (MIC) of the extract was found to be $5 \mathrm{mg} / \mathrm{ml}$ against Pseudomonas sp and Staphylococcus aureus, indicating broad spectrum activity. Results were discussed in respect to traditional treatment of epiglottitis.
\end{abstract}

Key words: Antimicrobial, medicinal plant, leofloxacin, crude leaf extract, epiglottits.

\section{Introduction}

Epiglottitis is the inflammation of the epiglottis-the flap tissue that sits at the base of the tongue, which keeps food away from going into the trachea (windpipe) so that one does not cough or choke after swallowing. Due to its place in the airway, swelling of the structure interferes with breathing and constitutes a medical emergency. Infections can cause the epiglottis to either obstruct or completely close off the windpipe making the condition life-threatening. The advent of Haemophilus influenza type b (Hib) vaccine has reduced the incidence of epiglottitis but it has not been eliminated [1][2]

Epiglottitis involves bacterial infection of the epiglottis, most often caused by Haemophilus influenza type b, although some cases are attributable to Streptococcus pneumonia, Streptococcus agalactiae, Staphylococcus aureus, Streptococcus pyogenes, Pseudomonas sp, mycobacterium tuberculosis, Klebsiella sp, Viruses, local trauma. Streptococci $s p$ are becoming the major pathogen in acute epiglottitis now [3]. Patients with epiglottitis may present with any of the following; sore throat, muffled voice, drooling, fever, anterior neck tenderness, cough, irritability, ear pain, cervical lymphadenopathy, odynophagia. The child often appears acutely ill, anxious and has a very quiet shallow breathing with head held forward, insisting on sitting up in bed. The early symptoms are insidious but rapidly progressive, and swelling of the throat may lead to cyanosis and asphyxiation [4][5]. With more severe epiglottitis, dyspnoea, dysphagia, dysphonia, stridor (late finding indicates airway obstruction), respiratory distress may occur.

Epiglottitis is life-threatening and usually occurs in both children and adults. The disease occurs at any time, there is no one season that it is more prevalent. Death may occur rapidly if the condition is not recognized and complete airway obstruction occurs [6].

The use of herbal medicine by the traditional practioners for the treatment of diseases remains the main stay of health care system and is gaining increasing popularity especially among the rural populace in developing countries. Many of the herbal remedies used by herbal practioners are also employed therapeutically in orthodox medicine after the crude extracts have been greatly improved upon. In recent times more research programs have been going on to assay and improve the medicinal principles found in drugs for use in the development of new pharmacotherapeutic agents in the management and cure of diseases[7]

Parinari curatellifolia is a valuable and cherished medicinal plant in which different parts of the plant are widely used by the traditional herbalist in the treatment of diabetes and other disease conditions and has been evaluated for its ant-diabetic activities [8]. The leaves of this plant as claimed by the traditional herbalist are utilized in the treatment of epiglottitis. However, there is no existing scientific evidence about the efficacy of the leaves of this plant. This work was therefore designed to investigate the pharmacological effects of the leaf extract of this plant with emphasis on its effect on the causative agents of epiglottitis.

The research was aimed at, determining the Phytochemical components of the crude extract of the leaf of Parinari curatellifolia, determining the antimicrobial activity of the crude extract of the leaf of Parinari curatellifolia on some selected causative agents of epiglottitis and comparing the efficacy of the crude extract of the leaf of Parinari curatellifolia with some selected antibiotics. 


\section{Identification of the Plant Material}

\section{Materials And Methods}

The plant was collected from Isu village in Eha-Amufu of Enugu State, Nigeria. It was identified and authenticated by a staff of Botany Department, University of Nigeria Nsukka. The voucher specimen was deposited at the biological science department of Modibbo Adama University of Technology, Yola.

\section{Source of the Test Organism}

The clinical isolates of Streptococcus sp, Staphylococcus aureus, Pseudomonas sp, and Klebsiella sp were obtained from Federal Medical Centre Yola, Nigeria. Each test bacterial strain was re-identified using standard bacteriological and biochemical methods. Stock cultures were maintained in nutrient agar slants at $4{ }^{\circ} \mathrm{C}$.

\section{Preparation of the plant extract}

The acetic acid, ethyl acetate, methanolic and aqueous extract of the leaf of the plant was prepared. The plant samples collected was air dried and ground using a milling machine. The powdered material was transferred into a Soxhlet apparatus and extracted separately in the Soxhlet extractor using ethyl acetate, methanol, acetic acid, and water for 24hrs each [9][10]. The extracts were concentrated to dryness and the residues obtained. The residues were transferred into pre-weighed sample containers, and stored at $4^{\circ} \mathrm{C}$ until when required for use.

\section{Phytochemical Screening}

The leaf extract of $P$. curatellifolia was analyzed for the presence of alkaloid, saponin, anthraquinone, steroids, tannin, flavonoid, reducing sugars and cardiac glycosides according to standard methods[11][10][9][12].

\section{Screening for alkaloids}

Three grams of the leaf extract was stirred with ethanol containing $3 \%$ tartaric acid. The filtrate was shared into 3 beakers and tested for alkaloids as follows: into the first beaker, Hagar's reagent was added, into the second beaker, Mayer's reagent was added and into the last beaker, Marquin's reagent was added. Precipitation in any of the 3 test indicated the presence of alkaloids.

\section{Screening for saponin}

About $0.5 \mathrm{~g}$ of the plant extract was shaken with water in a test tube. Frothing, which persist on warming was taking as a preliminary evidence for the presence of saponin. Few drops of olive oil was added to $0.5 \mathrm{~g}$ of the extract and vigorously shaken. Formation of soluble emulsion in the extract indicated the presence of Saponin [11][13].

\section{Screening for tannin}

About $0.5 \mathrm{~g}$ of the extract was added to $10 \mathrm{ml}$ of freshly prepared potassium hydroxide $(\mathrm{KOH})$ in a beaker and shaken to dissolve. A dirty precipitate was observed indicating the presence of tannin.

\section{Screening for steroids (Salkowski's test)}

About $100 \mathrm{mg}$ of $P$. curatellifolia leaf extract was dissolved in $2 \mathrm{ml}$ of chloroform. Sulphuric acid was carefully added to form a lower layer. A reddish brown color at the interface was an indicative of the presence of steroidal ring [10].

\section{Screening for flavonoid}

About $2 \mathrm{~g}$ of the powdered leaves were completely detained with acetone. The residue was extracted in warm water after evaporating the acetone in a water bath. The mixture was filtered while, still hot. The filtrate was cooled and used. $5 \mathrm{ml}$ of $20 \% \mathrm{NaOH}$ was added to equal volume of the detained water extract. A yellow solution indicated the presence of flavonoid.

\section{Screening for anthraquinone (Borntrager's test)}

About $0.5 \mathrm{~g}$ of the extract was taken into a dry test tube and $5 \mathrm{ml}$ of chloroform added and shaken for 5 min. The extract was filtered and the filtrate was shaken with equal volume of $10 \%$ ammonia solution. A pink violet or red color in the ammonical layer (lower layer) indicated the presence of anthraquinone. 


\section{Screening for cardiac glycosides (Keller Killiani's test)}

About $100 \mathrm{mg}$ of extract was dissolved in $1 \mathrm{ml}$ of glacial acetic acid containing one drop of ferric chloride solution. This was under layered with $1 \mathrm{ml}$ of concentrated Sulphuric acid. A brown ring obtained at the interface indicated the presence of a de-oxy sugar characteristic of cardenolides.

\section{Determination of Viable Cell}

Serial dilutions of 24 hour broth cultures were prepared. $1 \mathrm{ml}$ of suspension was inoculated into nutrient agar plates labeled according to the dilutions used. They were incubated in an inverted position at $37^{\circ} \mathrm{C}$ for 24hrs. After the incubation, plates with number of colonies ranging from 30-300 were counted. Plates with spreaders were discarded. Numbers of viable cells were calculated as follows;

No of cells $/ \mathrm{ml}=$ No of colonies $/$ volume of sample $X$ dilution factor [14]

\section{Determination of Antimicrobial Activity of the Extract}

The test for sensitivity of each organism was done by the disc diffusion technique [15]. A number of sterile paper discs (diameter $5 \mathrm{~mm}$ ) were mixed completely with a reconstituted extract in a sterile $10 \mathrm{ml}$ glass beaker. The discs were allowed to remain in contact with the extract for at least an hour to enable them absorbs the extracts which became embedded in the discs. The discs were brought out and allowed to air dry. As control, a number of sterile paper discs (diameter $5 \mathrm{~mm}$ ) were also mixed the solvents without the extract. Each organism was cultured by the spread plate technique [16]. The test organisms were adjusted to $11 \times 10^{7} \mathrm{cell} / \mathrm{s} / \mathrm{ml}$. They were spread evenly on the surface of the agar medium with a sterile glass hockey. Then using a flame needle, the prepared sensitivity test discs were carefully picked and placed on top of the inoculated plate at some distance from one another. The plates were allowed to stand for about 5 minutes and incubated at $37^{\circ} \mathrm{C}$ in an electronic incubator. They were observed for 24hours for growth and possible clear zone around the disc as a mark of sensitivity to the test extract. The antimicrobial activity of the partially fractionated extract was also determined using disc diffusion method.

\section{Determination of the Minimum Inhibitory Concentration (MIC) of the Extract}

The minimum inhibitory concentration was determined as the least concentration of the extract which inhibits each test organism. 500mg of the extract was separately reconstituted in sterile distilled water and diluted to concentrations of $50,5,0.5,0.05,0.005 \mathrm{mg} / \mathrm{ml}$. The regenerated concentrations were used for the sensitivity test. After incubation, the plates were observed for inhibition zones. The list concentration which caused inhibition was taken to be the minimum inhibition concentration.

The efficacy of the plant extract was compared to that of cephalosporin (cefixime), leofloxacin, augumentine, oflaxicin, nitrofurantoin, cefuroxime, gentamicin, cefazidime. Some of these antibiotics are utilized in the management and treatment of the disease in the hospital.

\section{Ethical Consent}

All experiments were examined and approved by the appropriate ethics committee and were performed in accordance with the ethical standards laid down in the 1964 declaration of Helsinki.

\section{STATISTICAL ANALYSIS}

The results were subjected to a statistical software SPSS (version 15.0) for analysis. Results were expressed as Mean \pm SEM. Significant differences were determined using the student's t-test. Differences were considered significant if $\mathrm{p}<0.05$.

\section{Results}

Physical examination of the various leaf extracts of Parinari curatellifolia showed that the aqueous extract is a brownish-solid; methanol and ethyl acetate extract are greenish-black solid, while the acetic acid extract is a brownish-black solid. Out of 50g of the powdered leaf of Parinari curatellifolia, the percentage extracts recovered were as follows; water extract 5.6\%, methanol extract $12.14 \%$, ethyl acetate $18.62 \%$, and acetic acid $21.12 \%$

The Phytochemical screening of the plant revealed the presence of saponin, alkaloids, flavonoids, steroids, tannins, cardiac glycosides (Table 1). The antimicrobial activity of the various extracts revealed that there are zones of inhibition on the bacteria culture media, thus signifying the presence of antimicrobial activity of the extract against the microbial isolate used. The acetic acid extract gave inhibition zones ranging from 20.0$28.7 \mathrm{~mm}$ that of ethyl acetate gave inhibition zones ranging from $14.7-15.3 \mathrm{~mm}$. The methanol extract gave an inhibition zones ranging from $0.9-13.0 \mathrm{~mm}$, while that of water ranges from 11.7-13.0mm (Table 2). 
The Minimum Inhibitory Concentration(MIC) of the acetic acid extract which gave the highest zones of inhibition against the microbial isolates used revealed that the MIC for Streptococcus pyogenes and Pseudomonas $s p$ is $5 \mathrm{mg} / \mathrm{ml}$ while that for Klebsiella sp and Staphylococcus aureus is $50 \mathrm{mg} / \mathrm{ml}$ (Table 3).

The efficacy of this plant extract was compared to that of some standard antibiotics. Among the antibiotics used, leofloxacin $(5 \mu \mathrm{g})$ gave the highest inhibition zone of $29.3 \mathrm{~mm}$ against $P$ seudomonas $s p$, while the acetic acid extract gave $28.7 \mathrm{~mm}$ against the same organism. There is no significant difference between the two inhibition zones $(\mathrm{P}<0.05)$. However, other antibiotics as well as other solvent extracts gave some inhibition zones (Table 4 and 2)

\section{Discussion}

In the present study, crude extract of Parinari curatellifolia was found to be rich in some secondary metabolites which include saponin, alkaloids, flavonoids, steroids, tannins, and cardiac glycosides. The presence of these secondary metabolites with different mechanism of antimicrobial activities suggests that this plant may be a potential source of antibiotic.

Steroids have been reported to have antimicrobial properties. The correlation between membrane lipids sensitivity indicates the mechanism in which steroids specifically associate with membrane lipids and exerts its action causing leakages from liposomes [17]. Tannins were found to complex with protein through so called non specific forces such as hydrogen bonding and hydrophobic effect as well as covalent bond formation [18][19]. Thus the mode of antimicrobial action of tannin may be related to their ability to inactivate microbial adhesion, enzymes, cell envelop, transport proteins and metal ion complexation etc. They also complex with polysaccharides [20]. There is also evidence that tannins directly inactivate microorganisms [21]. Many human physiological activities such stimulation of phagocytic cells, host mediated tumor activities and a wide range of ant-infective actions have been attributed to tannins [18].

While alkaloids intercalates intercalate into cell wall and/or DNA and therefore disrupt the activities of the microorganism [22], saponins are found to complex with cholesterol to form pores in cell membrane bilayers. This complexation leads to cell lysis [23]. Their amphipathic natures also make them act as surfactants that can be used to enhance the penetration of macromolecules such as proteins through cell membranes [24].

Flavonoids are known to be synthesized by plants in response to microbial infection [25]. Flavonoids have been found in vitro to be effective antimicrobial substances against a wide array of microorganisms. Their activity is probably due to their ability to complex with extracellular and soluble proteins and to complex with bacterial cell walls. More lipophilic flavonoids may also disrupt microbial membranes [26].

\section{Conclusion}

It is obvious that the in-vitro antimicrobial activity observed in this study may be attributed to any of the secondary metabolites. It is also apparent that the active component responsible for the activity is highly soluble in acetic acid than any other solvent. The actual component responsible for the observed activity, whether single or compound remains to be elucidated.

Table 1. Results of the Phytochemical Screening of P.curatellifolia Leaf Extracts

\begin{tabular}{lccccccc}
\hline Extracting solvent & SAP & CG & ALK & FL & ST & TA & AQ \\
\hline Water & + & + & + & + & + & + & - \\
Methanol & + & + & + & + & + & + & - \\
Ethyl acetate & + & + & + & + & + & + & - \\
Acetic acid & + & + & + & + & + & + & -
\end{tabular}

Note: $+=$ present $-=$ absent, $\mathrm{SAP}=$ Saponin, $\mathrm{CG}=$ Cardiac glycosides, $\mathrm{ALK}=$ Alkaloids, $\mathrm{FL}=$ Flavonoids, $\mathrm{ST}=$ Steroids, $\mathrm{TA}=$ Tannin, $\mathrm{AQ}=$ Anthraquinone

Table 2. Results of Antibacterial Activity of Leaf Extracts of $P$. curatellifolia.

Extracting solvent and inhibition zones (mm)

\begin{tabular}{lcccc} 
Microorganisms & Water $(\mathrm{mm})$ & Methanol $(\mathrm{mm})$ & Ethyl acetate $(\mathrm{mm})$ & Acetic acid $(\mathrm{mm})$ \\
\hline Streptococcus pyogenes & $11.7 \pm 1.2$ & $09.0 \pm 0.6$ & $14.7 \pm 0.9$ & $20.0 \pm 0.6$
\end{tabular}




$\begin{array}{lllll}\text { Staphylococcus aureus } & 13.7 \pm 1.3 & 10.0 \pm 0.6 & 16.3 \pm 0.9 & 28.3 \pm 0.3 \\ \text { Klebsiella sp } & 12.3 \pm 1.5 & 12.0 \pm 0.6 & 14.7 \pm 2.3 & 22.3 \pm 0.3 \\ \text { Pseudomonas } s p & 13.0 \pm 1.2 & 13.0 \pm 0.6 & 15.3 \pm 1.8 & 28.3 \pm 0.3\end{array}$

Results are express as mean \pm SEM

Table 3: Minimum inhibitory concentration of the acetic acid extract

\begin{tabular}{lccccc}
\hline & \multicolumn{5}{c}{ Extract concentration $(\mathrm{mg} / \mathrm{ml})$} \\
\cline { 3 - 6 } Microorganism & $50 \mathrm{mg} / \mathrm{ml}$ & $5 \mathrm{mg} / \mathrm{ml}$ & $0.5 \mathrm{mg} / \mathrm{ml}$ & $0.05 \mathrm{mg} / \mathrm{ml}$ & $0.005 \mathrm{mg} / \mathrm{ml}$ \\
\hline Streptococcus pyogenes & - & - & + & + & + \\
Staphylococcus aureus & - & + & + & + & + \\
Klebsiella sp & - & + & + & + & + \\
Pseudomonas sp & - & - & + & + & + \\
\hline
\end{tabular}

Note: - indicates no growth, + indicates growth

Table 4. Results of antibacterial activities of some standard antibiotics.

\begin{tabular}{|c|c|c|c|c|c|c|c|c|}
\hline \multirow[b]{2}{*}{ Microorganisms } & \multicolumn{7}{|c|}{ Standard Antibiotics and Inhibition Zone (mm) } & \multirow[b]{2}{*}{ CAZ } \\
\hline & AUG & GEN & LEO & CXM & NIT & OFL & CRX & \\
\hline Streptococcus pyogenes & $6.0 \pm 0.6$ & $5 \quad 13.6 \pm 1.6$ & $29.0 \pm 0.3$ & $11.3 \pm 0.9$ & $8.0 \pm 0.6$ & $14.0 \pm 0.6$ & - & - \\
\hline Staphylococcus aureus & - & $16.3 \pm 0.9$ & $25.0 \pm 0.6$ & - & $22.3 \pm 0.9$ & - & - & - \\
\hline Pseudomonas sp & - & $14.7 \pm 0.3$ & $29.3 \pm 0.9$ & $24.0 \pm 0.6$ & $15.7 \pm 1.2$ & $24.7 \pm 0.9$ & $10.3 \pm 0.9$ & - \\
\hline Klebsiella sp. & - & $13.7 \pm 0.9$ & $29.3 \pm 0.3$ & - & $22.3 \pm 0.9$ & - & - & - \\
\hline
\end{tabular}

Results are express as mean \pm SEM

$\mathrm{AUG}=$ Augumentin, GEN $=$ Gentamicin, $\mathrm{LEO}=$ Leofloxacin, $\mathrm{CXM}=$ Cefixime, $\mathrm{NIT}=$ Nitrofurantoin,

$\mathrm{CRX}=$ Cefuroxime, $\mathrm{CAZ}=$ Cefazidime, $\mathrm{OFL}=$ Oflaxicin

- indicates no inhibition zones

\section{References}

[1]. J.S. Keyser, C.S Derkay. Haemophilus influenza type b epiglottitis after Immunization with HaOC conjugates vaccine. Am J Otolaryngol 15(6), 1994, 436-43

[2]. J. McEwan, W. Giridharan, R.W. Clarke, P. Shears, Pediatric acute epiglottitis: not a disappearing entity. Int. J Pediatric.Otolaryngol. 67(4), 2003, 317-21.

[3]. H. Faden, The dramatic change in the epidemiology of pediatric epiglottitis. Pediatr. Emerg Care. 2006 22(6):443-4.

[4]. D.S. Parsons, R.B. Smith, E.A. Mair, L.J. Dlabal, Unique case presentation of acute epiglottic swelling and a protocol for acute airway compromise. Laryngoscope. 106, 1996, 1287-91.

[5]. E.Y. Wong, R.G. Berkowitz, Acute epiglottitis in adults: The Royal Melbourne Hospital Experience. ANZ J Surg. 71(12), 2001, 7403.

[6]. S. Berge, B. Trollfors, O. Nylen, Incidence, etiology, and prognosis of acute epiglottitis in children and adults in Sweden. Scand J Infect Dis. 28(3), 1996, 261- 4 .

[7]. A. Sofowara, Medicinal plants and Traditional medicine in Africa (Spectrum Books Ltd, Ibadan, Nigeria, 1993).

[8]. S.O Ogbonnia, F.E. Nkemehule, E.N. Anyika, Evaluation of acute subchronic toxicity of Starchytarpheta angustifolia (Mill) extract in animals. J Biotechnol. 8(9), 2009, 1793-1799.

[9]. J.B. Harborne, Phytochemical methods (Chapman and Hall, Ltd. London, 1973) 49-188

[10]. A. Sofowora, Medicinal plants and traditional medicine in Africa. (John Wiley and sons New York, 1982) 251.

[11]. O.O. Odebiyi and E.E. Sofowora, Phytochemical screening of Nigerian Medicinal plants. LIoydia, 41, 1978, 234-246.

[12]. D. M. Onwukeame, T.B. Ikuegbvweha, C.C. Asonye, Evaluation of Phytochemical constituents, antibacterial activities and effects of exudates of Pycanthus angolensis weld warb (mysristicaeceae) on corneal ulcers in rabbit. Trop. J. Pharm. Res. 6(2), 2007, 725-730.

[13]. J. Ngbede, R.A. Yakubu, D.A. Nyam, Phytochemical screening for active compounds in Canarium schweinfurthii (Atili) leaves from Jos North, Plateau state, Nigeria. Research Journal of Biological Science. 3(9), 2008, 1076-1078. 
[14]. S. Kanika, Manual of Microbiology: Tools and Techniques. (Ane Books Pvt ltd, 2009) 216

[15]. M. Cheesebrough, District Laboratory Practice in Tropical Countries. (Cambridge University Press UK, 2000) 1063-70.

[16]. C.S Pelczar, E.C. Chan, Laboratory Exercise in Microbiology. (Black Dot. Inc. New York, U.S.A., 1977) 26-31

[17]. F.E. Raquel, Bacterial lipid composition and the antimicrobial efficacy of cationic steroid compounds. Biochemical et Biophysica Acta, 2007 2500-2509.

[18]. E. Haslam, Natural polyphenols (vegetable tannins) as drugs: possible modes of action.J Nat Prod. 59, 1996, 205-215.

[19]. J.L. Stern, A.E. Hagerman, P.D. Steinberg, P.K. Mason, Phlorotannin-protein interactions. J Chem Ecol. 22, 1996, 1887-1899.

[20]. C. Ya, S.H. Gaffney, T.H. Lilley, E. Haslam, Carbohydrate-polyphenol complexation, Chemistry and significance of condensed tannins (New York; Plenum Press, 1988) 553

[21]. H.E. Brownlee, A.R. McEwen, J. Hedger, I.M. Scott, Anti-fungal effects of cocoa tannin on the witches' broom pathogen Crinipellis perniciosa. Physiol Mol Plant Pathol. 36, 1990, 39-48.

[22]. J.D. Phillipson, M.J. O'Neill, New leads to the treatment of protozoal infections based on natural product molecules. Acta Pharm Nord. 1, 1987, 131-144.

[23]. 23. G. Francis, K. Zohar, P.S. Harinder, K.B. Makkar, The biological action of saponins in animal systems: a review . British Journal of Nutrition. 88 (6), 2002, 587-605.

[24]. R.M. Zablotowics, R.E. Hoagland, S.C. Wagner, Effect of saponins on growth and activity of rhizosphere bacteria. Adv. Exp. Med. Biol. 405, 1996, 83-95.

[25]. R.A. Dixon, P.M. Dey, C.J. Lamb, Phytoalexins: enzymology and molecular biology. Adv Enzymol. 55, 1983, 1-69

[26]. H. Tsuchiya, M. Sato, T. Miyazaki, S. Fujiwara, S. Tanigaki, M. Ohyama, T. Tanaka, M. Iinuma. Comparative study on the antibacterial activity of phytochemical flavanones against methicillin-resistant Staphylococcus aureus. Ethnopharmacol. 50, 1996, $27-34$.

\section{Acknowledgement}

The authors are very grateful to the Managing Director of Peace Specialist Hospital Yola, Dr. Niyi, for given them the privilege to use his laboratory during the research periods. They are also grateful to the laboratory management of Federal Medical Centre, Yola and Specialist Hospital, Yola for their assistance in isolation and identification of the organisms used in this research. The authors are also indebted to the Chief Laboratory Technologist, Biochemistry Department, Modibbo Adama University of Technology Yola, Mr Raji, for his advice and assistance in the extraction process. 